\title{
Proteasome inhibitors modulate chemokine production in lung epithelial and monocytic cells
}

\author{
A. Gerber*, A. Heimburg*, A. Reisenauer*, A. Wille*, T. Welte\#, F. Bühling*
}

\begin{abstract}
Proteasome inhibitors modulate chemokine production in lung epithelial and monocytic cells. A. Gerber, A. Heimburg, A. Reisenauer, A. Wille, T. Welte, F. Bühling. (C) ERS Journals Ltd 2004.

ABSTRACT: Proteasome inhibition has become a target for antitumour and antiinflammatory therapy. The present study investigated the influence of cysteine proteinase and proteasome inhibitors on chemokine production in lung epithelial cells and monocytic cells.

The lung carcinoma cell lines A549, SK-MES, NCI-H727, virus-transformed bronchial epithelial cell line BEAS-2B, primary lung epithelial cells, and the acute monocytic leukaemia cell lines Mono-Mac-6 and THP-1 were incubated with proteasome ( $\mathrm{N}$-acetyl-L-leucyl-L-leucyl-L-norleucinal (ALLN), $\beta$-lactone) or cysteine proteinase inhibitor (L-trans-Epoxysuccinyl-Leu-3-methylbutylamide-ethyl ester) and the influence on chemokine production (interleukin-8: IL-8, monocyte chemoattractant protein-1, RANTES) was quantified at protein and mRNA levels.

Inhibition of proteasome activity by ALLN and $\beta$-lactone resulted in significantly increased IL-8 secretion (5- to 22-fold). Cysteine proteinase inhibitors did not influence chemokine production. The simultaneous rise in IL-8 mRNA was caused by an increased half-life of mRNA and increased RNA synthesis. Moreover, analysis of transcription factor activation revealed induction of activator protein-1 (c-Jun) activity by proteasome inhibition, whereas nuclear factor-kB (p50 and p65) was not activated. The significant increase in IL-8 production after proteasome inhibition was also observed in primary lung epithelial cells and in monocytic cells. In addition, the secreted IL-8 was biologically active as shown by the neutrophil chemotaxis assay.

In conclusion, it was shown that proteasome inhibitors stimulate interleukin-8 secretion in lung epithelial cells and monocytic cells, thus recruiting neutrophils.

Eur Respir J 2004; 24: 40-48.
\end{abstract}

*Institute of Immunology, and ${ }^{*}$ Dept of Pneumology and Critical Care, Otto von Guericke University, Magdeburg, Germany.

Correspondence: A. Gerber, Institute of Immunology, Otto von Guericke University, Magdeburg, Leipziger Strasse 44, 39120 Magdeburg, Germany.

Fax: 493916715852

E-mail: annegret.gerber@medizin.unimagdeburg.de

Keywords: Interleukin-8

lung epithelial cell

monocytic cell

proteasome inhibitor

Received: July 92003

Accepted after revision: March 82004

This work was supported by the grant DKH 10-1355-Ge 1 from the Deutsche Krebshilfe.
The ubiquitin-proteasome pathway regulates the turnover of many short-lived regulatory proteins involved in the cell cycle, apoptosis, signal transduction, and transcription [1]. Pharmacological intervention, which modulates the half-life of these cellular proteins, has become a therapeutic target [2]. Inhibition of proteasome function results in delayed tumour growth [3] and sensitisation of cells to apoptosis [4].

In addition to antineoplastic activity, proteasome inhibitors have been suggested as therapeutic agents in exacerbated inflammation. Proteosomal degradation of inhibitor $\kappa \mathrm{B}$ (IкB), inhibitor of the transcription factor nuclear factor (NF)- $\kappa \mathrm{B}$, is essential for the development of an inflammatory response. NF- $\kappa \mathrm{B}$ activates the expression of many genes encoding proinflammatory cytokines (interleukin (IL)-1, IL-6, tumour necrosis factor (TNF- $\alpha$ )), enzymes (cyclooxygenase-2, nitric oxide synthase), and adhesion molecules (intercellular adhesion molecule and vascular cell adhesion molecule) [5].

During the last decade it became clear that lung epithelial cells play a crucial role in the regulation of immune response mechanisms via secretion of cytokines, chemokines, and inflammatory mediators [6]. In lung epithelial cells the production of the chemokine IL-8 is induced by alveolar macrophage-derived proinflammatory cytokines IL- $1 \alpha / \beta$, TNF- $\alpha$ [7], bacterial cell wall products [8], and viruses [9, 10]. The stimulus-specific inducible IL- 8 production is regulated primarily at the level of gene transcription. The promotor region of many chemokine genes, including IL-8, monocyte chemoattactant protein-1 (MCP-1), and RANTES contains binding sites for the transcription factors $\mathrm{NF}-\kappa \mathrm{B}$, activator protein-1 (AP-1), and NF-IL-6 [11]. The TNF- $\alpha-$ induced IL-8 transcription required $\mathrm{AP}-1$ and $\mathrm{NF}-\kappa \mathrm{B}$, whereas the respiratory syncytial virus (RSV) induced only $\mathrm{NF}-\kappa \mathrm{B}$ binding activities. In contrast, stimulation by the reactive oxygen intermediate $\mathrm{H}_{2} \mathrm{O}_{2}$ involved activation and binding of AP-1 only [11]. Proteasome inhibition reversed the effect of TNF- $\alpha$ on the transcriptional activity of the IL-8 gene [12].

Recently, it was reported that proteasome inhibitors can upregulate IL-8 secretion by AP-1 induction despite a complete suppression of $\mathrm{NF}-\kappa \mathrm{B}$ activity. AP-1 activation was associated with increased mitogen-activated protein kinase (MAPK) activation [13]. Although this was demonstrated for the lung carcinoma epithelial cell line A549 and the human embryonic kidney cell line HEK293, the question remains open whether this effect is cell type specific or more universal.

The aim of this study was to investigate whether IL-8 expression is upregulated specifically in A549 cells, or whether proteasome inhibitors stimulate IL-8 secretion nonspecifically in different transformed and primary lung epithelial cells, as well as in cells of myeloid origin. Furthermore, the current study investigated the effect of 
proteasome inhibitors on the secretion of chemokines other than IL-8.

\section{Material and methods}

\section{Cells and inhibitors}

The epithelial cell lines: A549, derived from an alveolar lung carcinoma; SK-MES-1, derived from a lung squamous cell carcinoma; and Mono-Mac-6 and THP-1, which were isolated from patients with acute monocytic leukaemia; were obtained from DSMZ (Deutsche Sammlung von Mikroorganismen und Zellkulturen $\mathrm{GmbH}$ (a German collection of microorganisms and cell cultures) Braunschweig, Germany). NCI-H727, a bronchial epithelial carcinoid line, was obtained from the American Type Culture Collection (Manassas, Virginia, USA). The virus-transformed lung epithelial cells BEAS-2B were provided by A. Gillissen (Robert-KochKlinik, Klinikum St. Georg, Leipzig, Germany). The primary bronchial/tracheal epithelial cells (normal human bronchial epithelial cells; NHBE), and the small airway epithelial cells (SAEC) were purchased from Clonetics (Walkersville, MD, USA). Cell lines were grown in basal Iscove's medium (Biochrom KG, Berlin, Germany) supplemented with 10\% foetal calf serum, $1 \%$ antibiotic-antimycotic solution, and $1 \mathrm{mM}$ HEPES (Life Technologies, Eggenstein, Germany) at $37^{\circ} \mathrm{C}$ and $5 \% \mathrm{CO}_{2}$. Before incubation with inhibitors cells were maintained in Iscove's medium for $24 \mathrm{~h}$. The medium was replaced with serum-free HAM's F-12 medium (Biochrom KG, Berlin, Germany), and inhibitors were added at the indicated concentrations: N-Acetyl-L-leucyl-L-leucyl-Lnorleucinal (ALLN) - calpain inhibitor I, L-trans-epoxysuccinyl-leu-3-methylbutylamide-ethyl ester (E-64d) (BACHEM, Heidelberg, Germany), Clasto-Lactacystin $\beta$-lactone - Omuralide (Calbiochem, Bad Soden, Germany). A549 cells were pretreated with mitogen-activated protein/ERK kinase (MEK)1/2 inhibitor U0126 (Cell Signalling Technology Beverly MA, USA), p38 inhibitor SB203580 (Upstate, Charlottesville VA, USA), and c-Jun N-terminal kinase (JNK) inhibitor SP600125 (Merck Biosciences GmbH, Darmstadt, Germany) or with the equivalent amount of dimethylsulphoxide (DMSO) vehicle before addition of proteasome inhibitors.

\section{Quantitative RT-PCR}

For RT-PCR experiments, total RNA was isolated from cells using NucleoSpin II (Macherey-Nagel GmbH, Düren, Germany). Total RNA $(1.5 \mu \mathrm{g})$ was reverse transcribed by the first strand DNA synthesis kit (Amersham Pharmacia Biotech, Freiburg, Germany). The PCR reaction was optimised with the following primer pairs $\left(5^{\prime}-3^{\prime}\right)$ : IL-8 sense ATG ACT TCC AAG CTG GCC GTG, IL-8 antisense TCT CAG CCC TCT TCA AAA ACT TCT, $\beta$-actin sense TGA CGG GGT CAC CCA CAC TGT GCC CAT CTA, and $\beta$-actin antisense CTA GAA GCA TTT GCG GTG GAC GAT GGA GGG. DNA amplification using LightCycler (Idaho Technologies, Idaho Falls, ID, USA), verification of product specificity, and calculation of mRNA concentration were performed as previously described [14].

\section{Chemokine measurement}

Commercially available ELISA kits were used (R\&D Systems, Minneapolis, MN, USA) for the detection of human IL-8, RANTES, and MCP-1 in culture supernatants.

\section{Proliferation assay and cell cycle analysis}

A549 cells $\left(10^{4}\right.$ cells $\left.\cdot 100 \mu \mathrm{L}^{-1}\right)$ were incubated in serum-free HAM's F-12 medium in the presence of different concentrations of inhibitors E-64d $(50 \mu \mathrm{M})$, ALLN $(50 \mu \mathrm{M})$, and $\beta$ lactone $(25 \mu \mathrm{M})$, for $48 \mathrm{~h}$. For the last $16 \mathrm{~h} 0.5 \mu \mathrm{Ci}\left[{ }^{3} \mathrm{H}\right]-$ thymidine was added to the cultures. After harvesting, the radioactivity incorporated into the DNA was measured by liquid scintillation counting (1450 MicroBeta Trilux, PerkinElmer Wallac GmbH, Freiburg, Germany). For cell cycle analysis after inhibitor treatment, $10^{6}$ cells were fixed in $10 \mathrm{~mL} 75 \%$ ice cold ethanol for at least $2 \mathrm{~h}$. After washing, $5 \mathrm{~mL}$ of cold $0.25 \%$ Triton X-100 in PBS was added to the pellet and incubated on ice for $5 \mathrm{~min}$. Following a centrifugation step, cells were resuspended in $0.5 \mathrm{~mL}$ propidium iodide solution $\left(10 \mu \mathrm{g} \cdot \mathrm{mL}^{-1}\right)$ containing $50 \mu \mathrm{g} \cdot \mathrm{mL}^{-1}$ RNase A. After $20 \mathrm{~min}$ incubation, cells were acquired on a FACSCalibur flow cytometer using CellquestPro software (Becton Dickinson, San Jose, CA, USA). The percentage of cells in $\mathrm{G} 0 / \mathrm{G} 1, \mathrm{~S}$, and $\mathrm{G} 2 / \mathrm{M}$ phases of the cell cycle was calculated using ModFit LT software.

\section{Transcription factor activation}

Nuclear extracts of A549 cells were prepared according to SCHREIBER et al. [15]. Protein concentration was determined using Micro BCA protein assay (Perbio Science, Bonn, Germany). Transcription factor activation of $\mathrm{NF}-\kappa \mathrm{B}(\mathrm{p} 50)$, $\mathrm{NF}-\kappa \mathrm{B}$ (p65), and of the AP-1 family was determined by using the respective TransAM kits (Active Motif, Rixensart, Belgium).

\section{Nuclear run-on assay}

Nuclear run-on assays were performed using isolated nuclei of A549 cells after incubation with and without inhibitors. In brief, cells were harvested, washed twice in ice-cold PBS, and lysed in buffer containing $10 \mathrm{mM}$ Tris- $\mathrm{HCl}, 3 \mathrm{mM} \mathrm{MgCl}$, $10 \mathrm{mM} \mathrm{NaCl}$, and $0.5 \% \mathrm{NP}-40$. The frozen nuclei were incubated with $1 \mathrm{mM}$ of each nucleotide (ATP, CTP, GTP, and UTP; Amersham Pharmacia Biotech) for $30 \mathrm{~min}$ at $30^{\circ} \mathrm{C}$. Total RNA was isolated from the nuclei, reversed transcribed and quantitative RT-PCR was performed.

\section{Determination of RNA half-life}

A549 cells were incubated with the inhibitors, as described above for $24 \mathrm{~h}$. Actinomycin D $\left(10 \mu \mathrm{g} \cdot \mathrm{mL}^{-1}\right.$, Sigma Chemical Company, Taufkirchen, Germany), an inhibitor of RNA synthesis, was added for $4 \mathrm{~h}$. At different time points the specific IL-8 mRNA was quantified by RT-PCR.

\section{Isolation of polymorphonuclear granulocytes and the neutrophil chemotaxis assay}

A modified under-agarose technique was used as previously described [16]. The chemotactic peptide N-formyl-methionylleucyl-phenylalanine (fMLP; Sigma Chemical Company; $4 \times 10^{-7} \mathrm{M}$ ) and recombinant human IL-8 (R\&D Systems; $100 \mathrm{ng} \cdot \mathrm{mL}^{-1}$ ) as well as conditioned media from NCI-H727 cells containing IL-8 after incubation with and without proteasome inhibitors were used as stimuli. For blocking experiments recombinant human IL-8 or IL-8-containing supernatants of NCI-H727 cells were preincubated with an anti-IL-8 antibody (R\&D Systems) or the respective isotype 
control antibody (BD Biosciences; Heidelberg, Gemany) for $30 \mathrm{~min}$ at $37^{\circ} \mathrm{C}$.

\section{Statistical analysis}

Statistical analysis was performed using one-way analysis of variance to compare data in different groups. A p-value $<0.05$ was considered statistically significant.

\section{Results}

Proteasome inhibition suppressed DNA synthesis and induced cell cycle arrest

Proteasome inhibitors are known to induce disturbances in cell cycle progression leading to growth inhibition and/or induction of apoptosis. Incubation with ALLN or $\beta$-lactone was found to induce significant inhibition of DNA synthesis in a dose-dependent manner. At the inhibitor concentration of $50 \mu \mathrm{M}$, the percentage of DNA synthesis was decreased to $10 \%$ compared with untreated cells. In contrast, E-64d had no effect on DNA synthesis (fig. 1a). The viability of cells ranged between $95 \%$ and $99 \%$ and was not affected by the inhibitors as shown by trypan blue exclusion (data not shown). Treatment with $\beta$-lactone resulted in accumulation of $27 \%$ of cells in the G2/M phase compared with $8 \%$ and $7 \%$ in the untreated or E-64d-treated cells. Treatment of cells with ALLN arrested 15\% of cells in G2/M phase. Furthermore, ALLN resulted in accumulation of $28 \%$ of cells in the S- growth phase compared with $25 \%$ in $\beta$-lactone treated cells and $20 \%$ in E-64d treated and untreated cells, respectively (fig. 1b-e).

Proteasome inhibitors increased IL-8 secretion and decreased release of $M C P-1$

Treatment of lung epithelial A549 cells with proteasome inhibitors resulted in a dramatic increase in IL-8 secretion after $24 \mathrm{~h}$. This effect was more pronounced after incubation with ALLN (22-fold) compared with pretreatment with $\beta$-lactone (5-fold). In contrast, secretion of MCP-1 was significantly decreased after incubation of A549 cells with the proteasome inhibitors (2- to 3-fold). RANTES was not detectable under these conditions (data not shown). The cysteine proteinase inhibitor E-64d exerted no clear effect on chemokine release in A549 cells (fig. 2a). The dramatic stimulatory effect of proteasome inhibitors on IL-8 production was concentration dependent in the range $3.12-50 \mu \mathrm{M}$. Maximal IL-8 release after ALLN treatment was observed at $50 \mu \mathrm{M}$. For $\beta$-lactone, the highest IL-8 concentration was measured after incubation with $12.5 \mu \mathrm{M}$ inhibitor (fig. 2b).

IL-8 production after proteasome inhibition is accompanied by increased IL-8 $m R N A$ and prolonged $R N A$ half-life

To assess the effect of proteasome inhibitors on IL-8 mRNA expression, quantitative RT-PCR analysis was performed. A significant increase in IL-8 mRNA concentrations in A549 cells after incubation with ALLN (6-fold) and $\beta$-lactone (9-fold) was detected. The cysteine proteinase inhibitor E-64d reduced IL-8 mRNA (fig. 3a). Upregulation of the IL- 8 mRNA concentration after proteasome inhibition may be caused by transcriptional induction and/or prolonged RNA stability. ALLN and $\beta$-lactone
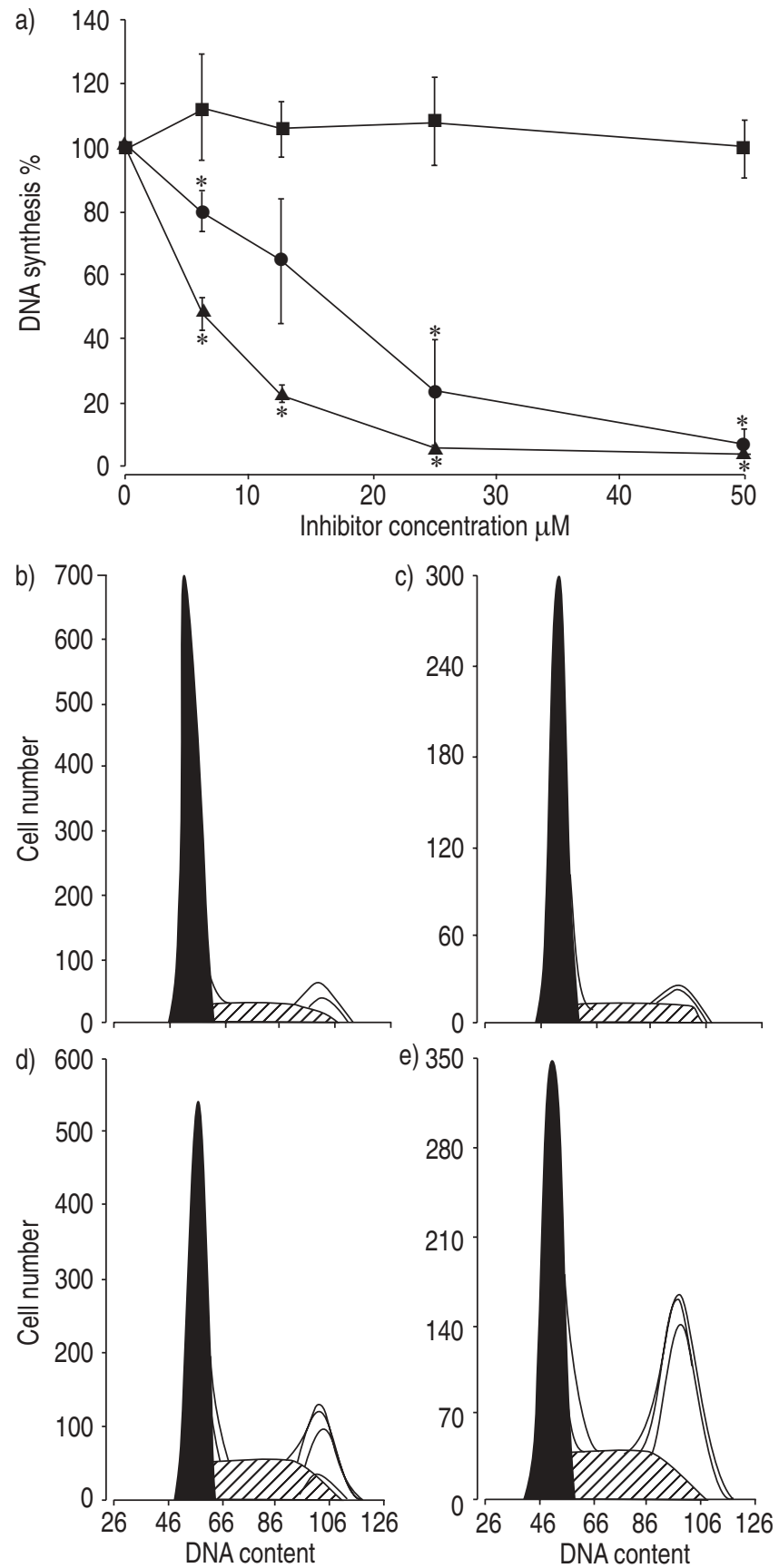

Fig. 1.- Proteasome inhibitors suppress DNA synthesis. a) Proliferation was expressed as \% DNA synthesis in relation to control cells without inhibitor treatment. The mean of untreated control cells was 34,007 counts per min. Results represent the mean \pm SEM of three independent experiments each performed in quadruplicate compared with untreated control cells. $\mathbf{\square}$ : E-64d; O: ALLN; $\boldsymbol{\Delta}$ : $\beta$-lactone. b-e) Histograms showing DNA content and cell number. These data represent one of four independent experiments: b) control; c) E-64d; d) ALLN; and e) $\beta$-lactone. $\square$ : cells in G0/G1 growth phase; $\mathbb{Z}$ : cells in $\mathrm{S}$ growth phase; $\square$ : cells in $\mathrm{G} 2 / \mathrm{M}$ growth phase. *: $\mathrm{p}<0.05$, compared with untreated controls.

treatment resulted in an increase in newly transcribed IL-8 mRNA compared with untreated control cells as shown by nuclear run-on assays (fig. 3b). The rate of decay of IL-8 mRNA was investigated using the RNA synthesis inhibitor actinomycin D. In untreated cells, incubation with actinomycin $\mathrm{D}$ resulted in a decrease of IL-8 mRNA. After proteasome inhibitor treatment a clear 

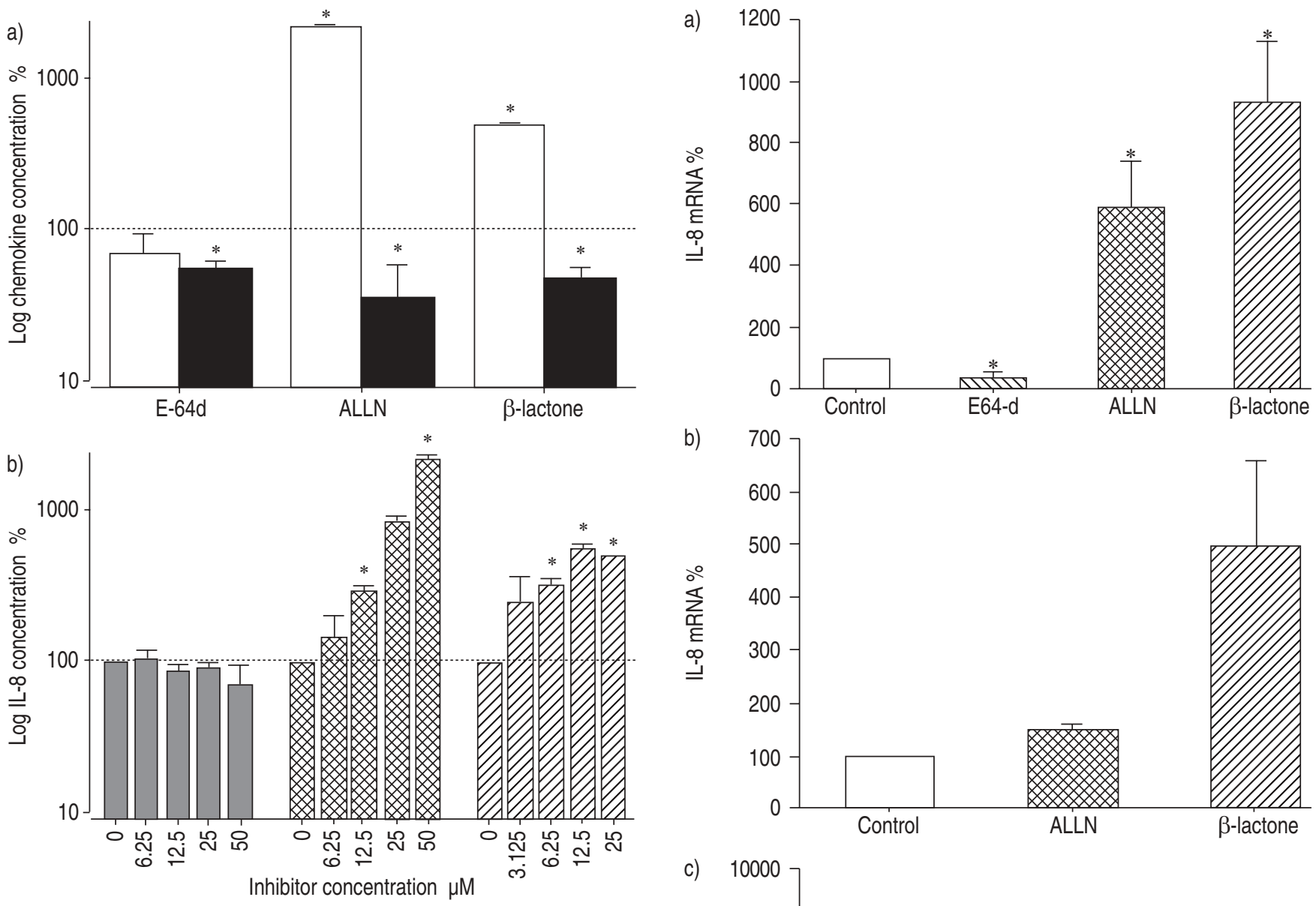

Fig. 2. - a) Proteasome inhibitors modulate chemokine production ( $\square$ : interleukin (IL)-8; $\mathbf{0}$ : monocyte chemoattractant protein (MCP)-1). A549 lung epithelial cells were incubated with the inhibitors E-64d $(50 \mu \mathrm{M})$, ALLN $(50 \mu \mathrm{M})$ and $\beta$-lactone $(25 \mu \mathrm{M})$ for $24 \mathrm{~h}$. The means of untreated control cells were $110 \mathrm{pg} \cdot \mathrm{mL}^{-1}$ IL-8 and $98 \mathrm{pg} \cdot \mathrm{mL}^{-1}$ MCP-1. b) The proteasome inhibition showed a dose-dependent effect on IL-8 secretion. ㅁ: E-64d; $\mathbf{D}$; ALLN; $\mathbb{Z}: \beta$-lactone. Data are presented as the percentage of untreated control cells. Data represent the mean \pm SEM of three independent experiments performed in duplicate. *: $\mathrm{p}<0.05$ versus control cells.

stabilisation of IL- 8 mRNA was observed (fig. 3c). These results demonstrate that the increase in IL- 8 mRNA was caused both by the increased RNA synthesis and the prolonged mRNA half-life.

\section{Proteasome inhibitors induce MAPK activation and AP-1 DNA binding activity}

To study AP-1 and NF- $\mathrm{B}$ activation, nuclear extracts of ALLN- or $\beta$-lactone-treated A549 cells were prepared. Enzyme immunoassays on immobilized oligonucleotides containing the $\mathrm{NF}-\kappa \mathrm{B}$ consensus site were performed. After proteasome inhibition NF- $\kappa \mathrm{B}(\mathrm{p} 50)$ or $\mathrm{NF}-\kappa \mathrm{B}$ (p65) activation was not detected (fig. $4 \mathrm{a}, \mathrm{b}$ ). In addition, the protease inhibitor E-64d showed no effect (data not shown). TNF- $\alpha$, which was used in control experiments, caused a significant increase in NF- $\kappa \mathrm{B}$ (p50) DNA-binding activity and a slight increase in NF- $\kappa \mathrm{B}$ (p65) DNA binding.

To investigate AP-1 activation, DNA binding of proteins derived from the Fos and Jun families were studied: c-Fos, FosB, Fra-1, Fra-2, c-Jun, JunB, and JunD. DNA binding

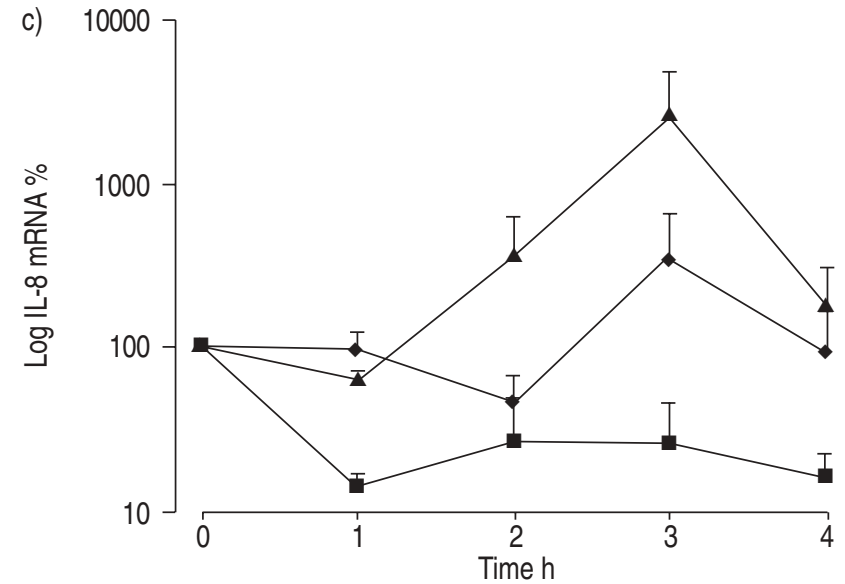

Fig. 3.- Interleukin (IL)-8 mRNA is upregulated after proteasome inhibition. a) A549 cells were pre-incubated with the inhibitors E-64d $(50 \mu \mathrm{M}), \operatorname{ALLN}(50 \mu \mathrm{M})$ and $\beta$-lactone $(25 \mu \mathrm{M})$. The relative amount of IL-8 mRNA was calculated in relation to $\beta$-actin mRNA. b) Transcription rates of the IL-8 gene in inhibitor-treated and untreated cells. c) IL-8 mRNA stability. 口: control; $\bullet$ : ALLN; $\boldsymbol{\Delta}$ : $\beta$-lactone. All values are means of three independent experiments (mean \pm SEM). *: $\mathrm{p}<0.05$ compared with control cells without treatment.

activity of c-Jun was significantly increased up to $166 \%$ by $\beta$-lactone, up to $125 \%$ by ALLN and up to a maximum activation of $176 \%$ by PMA (Phorbol 12-myristate 13-acetate: used as a positive control for AP-1 activation; fig. 4c). E-64d induced no c-Jun activity. In contrast, significantly induced FosB activation was found only after PMA stimulation (fig. 4d). The proteasome inhibitors ALLN and $\beta$-lactone as well as the cysteine protease inhibitor E-64d revealed no effect. The nuclear extracts of ALLN- or $\beta$-lactone-treated 

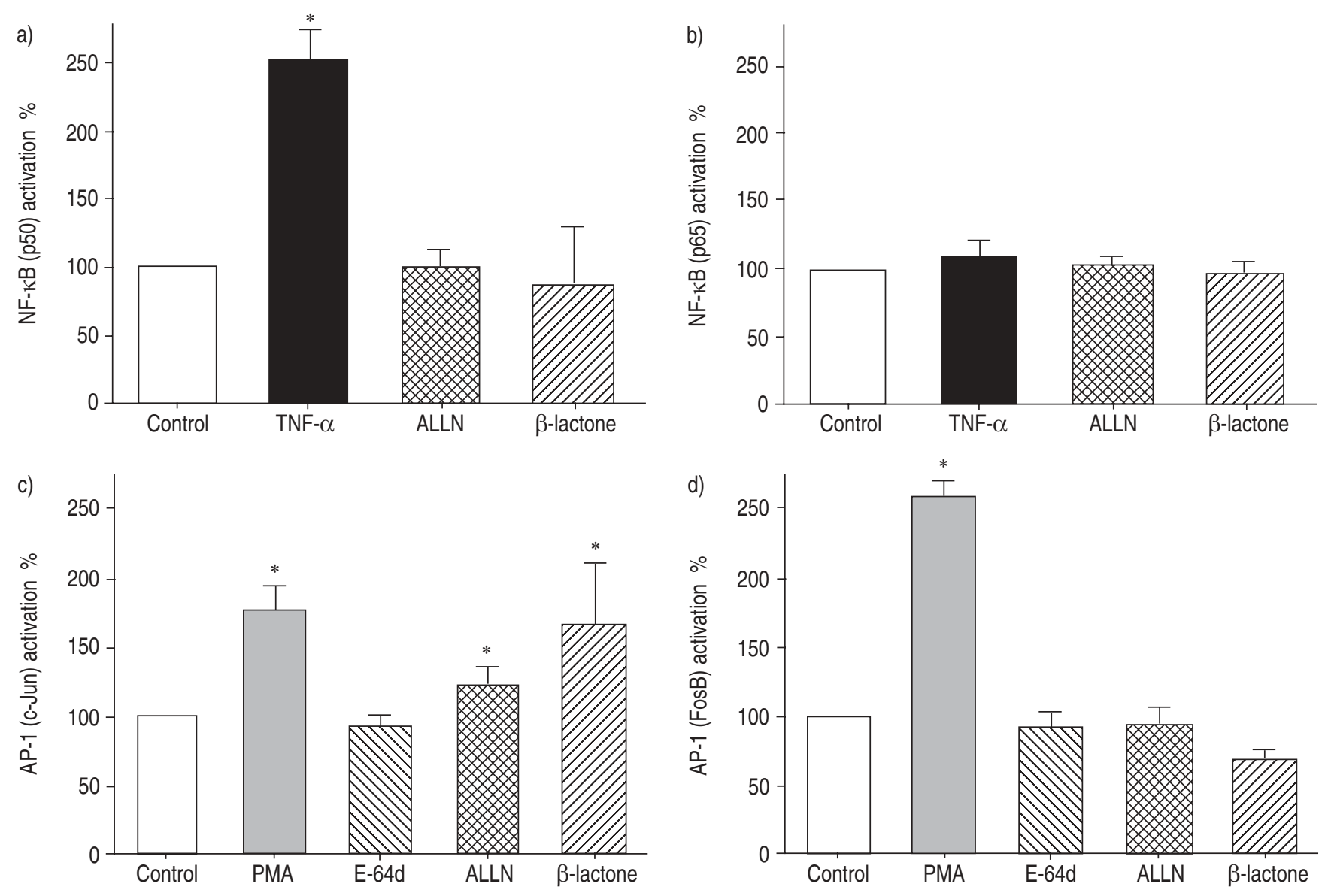

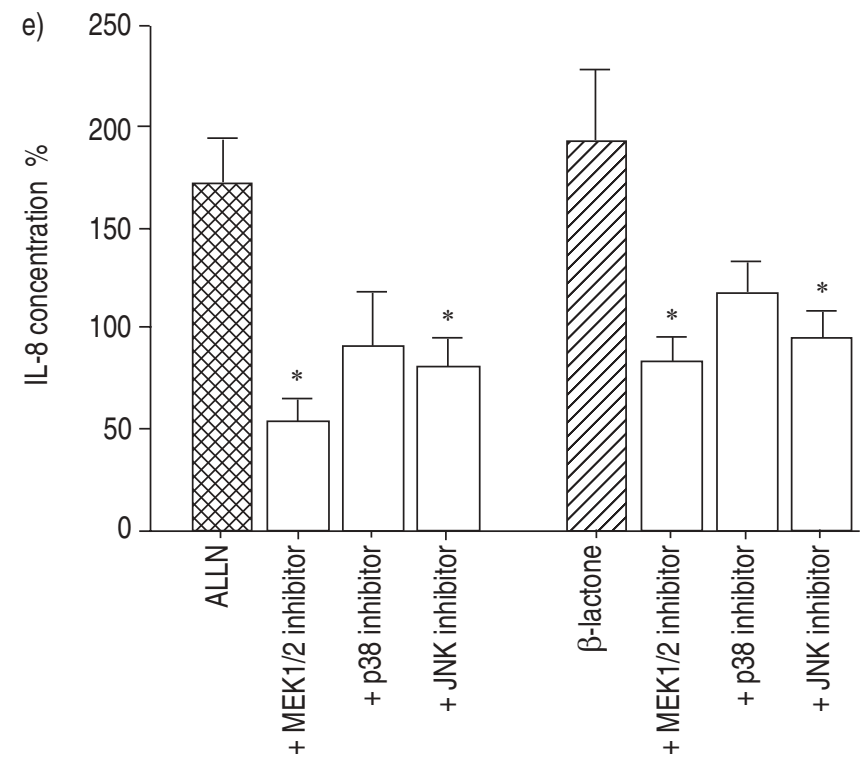

A549 cells showed no DNA binding activity for the other AP-1 isoforms c-Fos, Fra-1, Fra-2, JunB, and JunD (data not shown).

AP-1 induction depends on MAPK activation, therefore, the possible involvement of ERK, JNK and p38 in proteasome inhibitor-induced IL-8 production was examined. A549 cells were pretreated with the MAPK inhibitors U0129 (MEK1/2 inhibitor), SB203580 (p38 inhibitor), or SP600125 (stress-activated protein kinase/JNK inhibitor) before addition of proteasome inhibitors. Although the protein kinase inhibitors were used at high concentrations no cytotoxic effects were obtained. After $24 \mathrm{~h}$ incubation with these inhibitors the viability was $>97 \%$ as determined by Trypan blue exclusion (data not shown). The concentrations of protein kinase inhibitors chosen in this study are commonly used, and are known to sufficiently inhibit their target kinases in A549 cells [13, 17, 18]. 

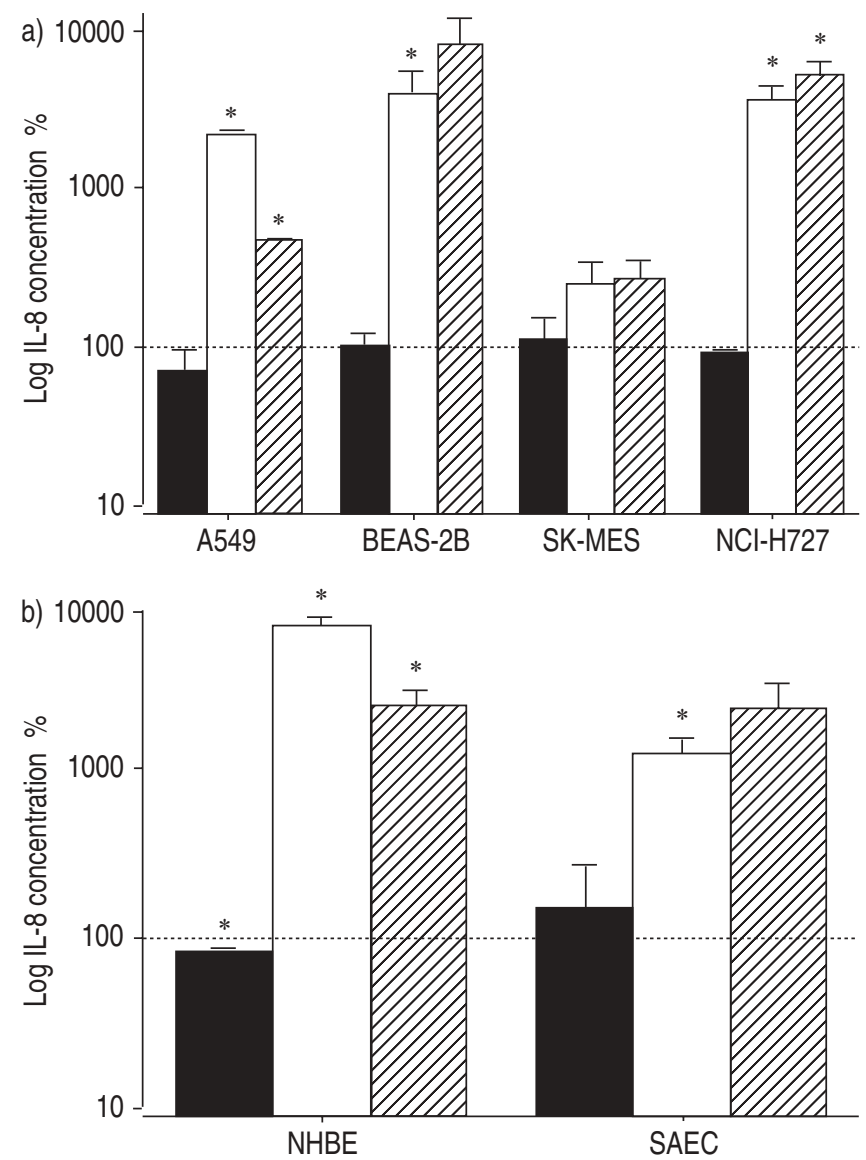

Fig. 5. - Proteasome inhibitors increase interleukin (IL)-8 secretion in different lung epithelial cells. Cells were incubated in the presence and absence of inhibitors ( $\mathbf{\square}$ : E-64d; $\square$ : ALLN; $\mathbb{Z}$ : $\beta$-lactone; …....... control). The following cells were used: a) epithelial lung tumour cell lines (A549, BEAS-2B, SK-MES, and NCI-H727); b) primary lung epithelial cells (normal human bronchial epithelial cells (NHBE) and small airway epithelial cells (SAEC)). Each result represents the mean \pm SEM of three independent experiments performed in duplicate. *: $\mathrm{p}<0.05$ compared with control cells without treatment.

All MAPK inhibitors reduced the ALLN- and $\beta$-lactoneinduced IL- 8 production. This effect was considered to be significant for MEK1/2 inhibitor and JNK inhibitor but not for p38 inhibitor (fig. 4e). These results suggest that proteasome inhibition leads to c-Jun-dependent AP-1 activity and subsequent IL-8 induction.

Induction of IL-8 expression is observed in different human lung epithelial cells

To elucidate whether proteasome inhibition leads to increased IL-8 release in different lung epithelial cells, A549, SK-MES-1, NCI-H727, BEAS-2B cells were analysed, along with primary NHBE and SAEC cells. In all cells, an increased IL-8 release was found after proteasome inhibition whereas the cysteine proteinase inhibitor had no effect. In BEAS-2B the increase in IL-8 production was 40-fold after ALLN inhibition and 83 -fold after $\beta$-lactone treatment. In NCI-H727 cells a 37-fold increase in IL-8 was found after ALLN inhibition and a 51-fold increase after $\beta$-lactone inhibition. SK-MES cells produced less IL-8 compared to A549, BEAS-2B, and NCIH727 (fig. 5a). In primary lung epithelial cells proteasome inhibition increased IL-8 expression more than 10-fold (fig. 5b).
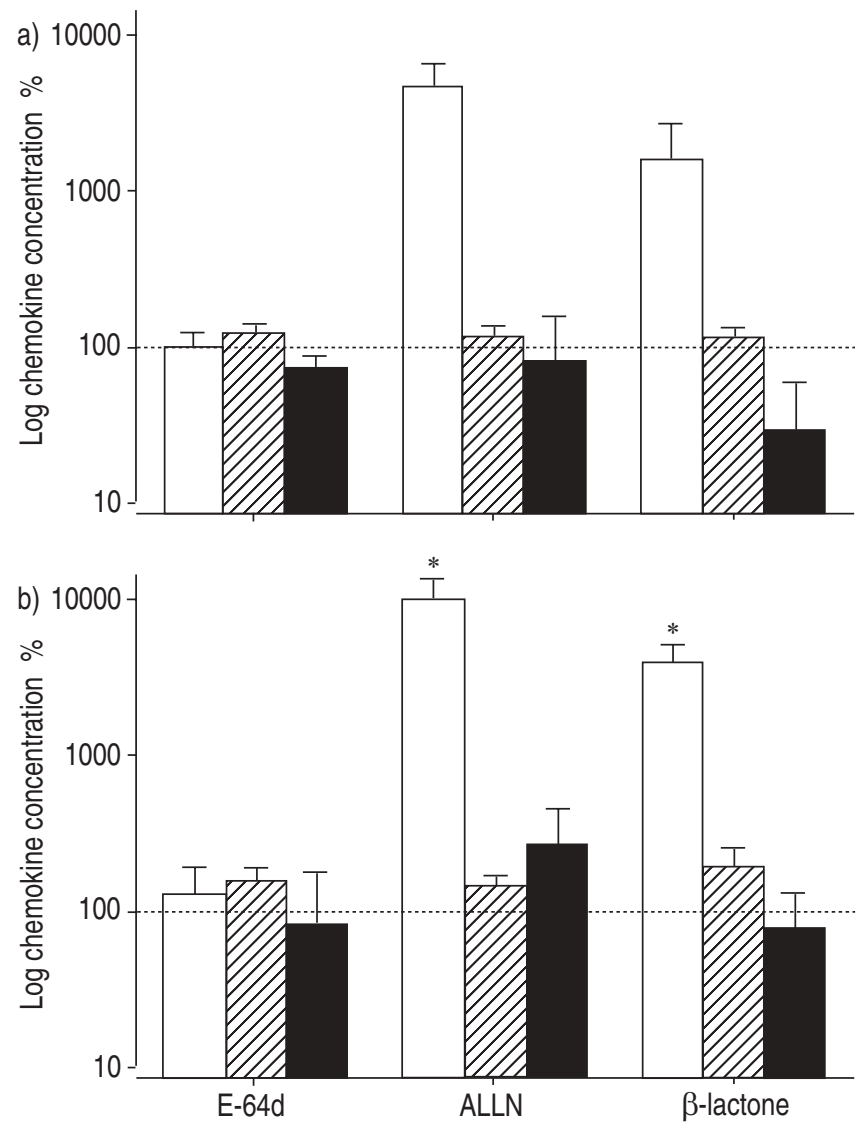

Fig. 6.-Proteasome inhibitors increase interleukin (IL)-8 secretion in monocytic cells. a) Mono-Mac-6 and b) THP-1 cells were incubated in the presence or absence of inhibitors and IL-8 ( $\square$ ), RANTES $(\mathbb{Z})$ and monocyte chemoattractant protein-1 (MCP-1; $\mathbf{0})$ were quantified. .......... control. Data are presented as the mean \pmSEM of three independent experiments. *: $\mathrm{p}<0.05$ compared with untreated controls.

\section{Increased IL-8 expression is observed monocytic cells}

Furthermore, the present study determined whether the effect of proteasome inhibitors was lineage-specific. For the acute monocytic leukemia cell lines Mono-Mac-6 and THP-1 an up-regulation of IL-8 release was found after incubation of cells with proteasome inhibitors. This effect was more pronounced for ALLN compared with $\beta$-Lactone (fig. 6). RANTES secretion showed no significant changes after proteasome inhibition. MCP-1 production was slightly decreased in both monocytic cell lines with the exception of ALLN-treatment in THP-1 cells. Taken together, these findings show that increased IL-8 secretion after proteasome inhibition is not a specific effect in A549 cells and can also be observed in other lung epithelial cells and in monocytic cells.

\section{IL-8 secreted after proteasome inhibition showed chemotactic activity}

To answer the question whether the secreted IL-8 is biologically active neutrophil chemotaxis assays were performed. NCI-H727 cells revealed higher IL-8 concentrations after proteasome inhibition compared with A549, therefore, cell culture supernatants were collected after incubation of NCI-H727 cells with ALLN $(50 \mu \mathrm{M})$ or without inhibitor. Supernatants of proteasome inhibitor-treated cells induced a 

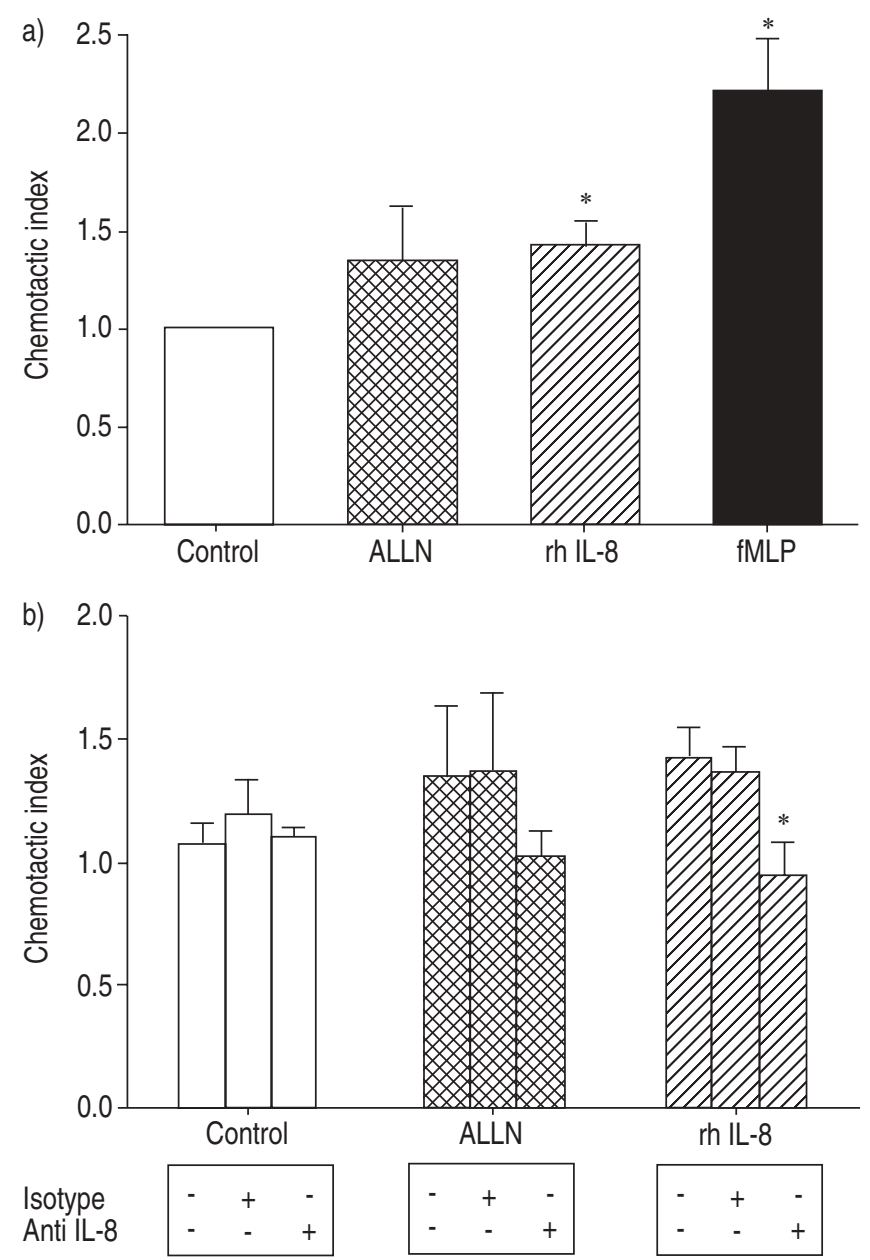

Fig. 7. - a) Interleukin (IL)- 8 secreted after proteasome inhibition is a biologically active chemokine. NCI-H727 cells were pre-incubated without or with the inhibitor ALLN $(50 \mu \mathrm{M})$ and supernatants were applied as a chemotactic stimulus in the neutrophil chemotaxis assay. The bacterial peptide fMLP and recombinant human IL-8 (rh IL-8) were used as positive controls for neutrophil chemotaxis. b) Supernatants of ALLN treated or untreated NCI-H727 were incubated in the presence $(+)$ or absence (-) of an anti-IL- 8 antibody or an isotype-matched control antibody $\left(10 \mu \mathrm{g} \cdot \mathrm{mL}^{-1}\right)$. The stimulation index was calculated as the relation of migration distances of stimulated migration to spontaneous migration. Data are presented as mean \pm SEM of at least three independent experiments performed in triplicate. ${ }^{*}: \mathrm{p}<0.05$ versus untreated control cells.

chemotactic response in neutrophils when compared with untreated cells. However, this effect failed to reach statistical significance (fig. 7a). Neutrophil chemotaxis induced by supernatants of ALLN-treated cells was blocked in the presence of an anti-IL-8 antibody whereas an irrelevant isotype control antibody had no effect (fig. 7b). These data show that proteasome inhibition induced release of biologically active IL-8.

\section{Discussion}

The aim of this study was to investigate the influence of proteasome inhibitors on IL-8 production from different lung epithelial cells and monocytic cells. To summarise the main results, a significant upregulation of biologically active IL-8 was found in different lung epithelial cells and primary lung epithelial cells, as well as in monocytic cells.

The cell permeable $\beta$-lactone is known to be a selective and potent inhibitor of the $20 \mathrm{~S}$ proteasome. E-64d is a membranepermeable, irreversible inhibitor of cysteine proteinases of the papain and calpain family. ALLN blocks calpains, cathepsins, and less potently the proteasome [19]. These inhibitors showed no toxic effects on the cells under the conditions used in the present study.

It was demonstrated that ALLN and $\beta$-lactone inhibited proliferation of A549 cells in vitro in a dose-dependent manner, whereas E-64d had no effect. Inhibition of proteasome function results in accumulation of short-lived proteins and, thus, causes an imbalance of the cell cycle regulatory components. Indeed, it was demonstrated that proteasome inhibitors ALLN and $\beta$-lactone perturb the cell cycle progression and lead to $\mathrm{G} 2 / \mathrm{M}$ arrest. These data are in agreement with previously published results for the proteasome inhibitor PS-341 [20], where an accumulation of the phase-related cyclins $\mathrm{B}$ and $\mathrm{A}$, in addition to a cell cycle blockade in the G2/M phase, was observed in nonsmall cell lung cancer cell lines.

Despite this antiproliferative effect, a dramatic increase in IL-8 secretion after proteasome inhibition was found. These effects of ALLN and $\beta$-lactone were due to inhibition of the proteasome rather than calpain or cysteine proteases, because E-64d had no effect on IL-8 expression. The data in the present study are in agreement with the results of Wu et al. [13] who showed that proteasome inhibitors alone induced IL-8 release after $18-24 \mathrm{~h}$. Analysing the secretion of other chemokines proteasome inhibitors are shown to upregulate the IL-8 secretion and downregulate MCP-1 production. Previous data concerning the effects of proteasome inhibition on the MCP-1 secretion are controversial. NAKAYAMA et al. [21] have shown that MCP-1 is induced after proteasome inhibition in rat mesangial cells. In contrast, in human arterial endothelial cells MCP-1 expression was downregulated by proteasome inhibitors [22, 23]. Taken together, these data suggest cell-type-dependent differences in NF- $\kappa \mathrm{B}$-independent regulation of MCP-1 gene expression. To the best of the authors' knowledge, there are no data available concerning the direct effects of proteasome inhibitors on RANTES production in airway epithelial cells.

To address the question of whether this effect is specific for A549 cells, different airway epithelial cells were tested and, because of their important role in the production of proinflammatory cytokines and chemokines, myeloid cells. The current study demonstrated for the first time that primary lung epithelial cells, as well as myeloid cells, showed IL-8 induction in response to proteasome inhibition. Previous reports demonstrated NF- $\mathrm{NB}$-independent induction of IL-8 after proteasome inhibition in human embryonic kidney cells [13], human endothelial cells, and in one out of three human glioblastoma cells [22]. Thus, the induction of IL-8 by proteasome inhibitors seems to be cell-type independent. However, some cell-type specific modulation may be caused by the different composition of the AP-1 complex.

Using quantitative RT-PCR the enhanced IL- 8 production was demonstrated to be accompanied by increased IL-8 mRNA levels. Besides transcriptional induction of IL-8, increased RNA stability was also found. Previously, in THP-1 cells an increased IL-8 mRNA stability was observed in the presence of the proteasome inhibitor PSI [24]. In contrast, HIPP et al. [22] excluded increased IL-8 RNA stability as a cause for IL-8 accumulation in MG132-treated arterial endothelial cells [22]. The reason for these contrasting observations may be cell-type specific. It has been shown that the proteasome possesses RNase activity and takes part in cellular RNA breakdown [25]. Therefore, the present authors hypothesised that proteasome inhibition prevents the proteasome associated RNase activity, thereby stabilising certain mRNA species including IL-8 mRNA [26]. 
The IL-8 promotor contains binding sites for the transcription factors AP-1, NF-IL-6 (also known as CCAAT/ enhancer-binding protein), and NF- $\kappa$ B. Several investigators were unable to demonstrate a role for NF-IL-6 in the regulation of IL-8 expression in A549 cells [27]. For many activators $\mathrm{NF}-\kappa \mathrm{B}$ has been shown to be the essential transcription factor for IL-8 induction. The cooperative interaction between $\mathrm{NF}-\kappa \mathrm{B}$ and $\mathrm{AP}-1$ produces maximum activity of IL-8 transcription [28]. However, IL-8 can also be induced independently of NF-кB. The present study data clearly indicate that IL-8 release induced by proteasome inhibition is independent of $\mathrm{NF}-\kappa \mathrm{B}(\mathrm{p} 50)$ and $\mathrm{NF}-\kappa \mathrm{B}(\mathrm{p} 65)$ but requires AP-1 (c-Jun) activation.

Furthermore, the effect of MAPK inhibitors to assess the role of p38, ERK, and JNK was investigated. The inhibitors SB203580, U0126 and SP600125 are widely used in A549 cells to examine the effect of selective MAPK pathway inhibitors on mediator release. NEWTON et al. [29] showed that IL-1 $\beta$ induced prostaglandin $\mathrm{E}_{2}$ release in A549 cells is prevented by the p38 inhibitor SB203580 (median effective concentration: $\left.\mathrm{EC}_{50} 0.18 \mu \mathrm{M}\right)$ and by the JNK inhibitor U0126 $\left(\mathrm{EC}_{50}\right.$ $0.8 \mu \mathrm{M})$. These results correlated with published values for p38 inhibition (SB203580, inhibitory concentration of $50 \%$ : $\mathrm{IC}_{50} 0.6 \mu \mathrm{M}$ ) and for MEK1/2 inhibition (U0126 $\mathrm{IC}_{50}$ $0.07 \mu \mathrm{M}$ and $0.06 \mu \mathrm{M}$, respectively) as determined by in vitro kinase assays $[30,31]$. The inhibitory profile for the novel JNK inhibitor SP600125 revealed selective inhibition of all three $\mathrm{JNK}$ isoforms ( $\mathrm{IC}_{50} 0.04-0.09$ ) [32]. The concentrations of the protein kinase inhibitors used in the present study have been shown to be effective in A549 cells [13, 17, 18]. The current study demonstrated that proteasome inhibitorinduced IL-8 release was significantly reduced by inhibitors of MEK1/2 and JNK. The inhibitor of p38 MAPK did not significantly affect ALLN or $\beta$-Lactone-mediated IL-8 induction. These results confirm the data of WU et al. [13] who showed that the proteasome inhibitors MG132 and lactacystin induce IL-8 through MEK- and JNK-dependent AP-1 stimulation.

In the present study, the authors have shown that lung epithelial tumour cells may drive local neutrophil recruitment and activation via increased release of biologically active IL-8 after proteasome inhibition. The question then arises of whether high IL-8 concentrations and neutrophil infiltration affect tumour progression. BELLOCQ et al. [33] demonstrated that high IL-8 levels and increased numbers of neutrophils in the bronchoalveolar lavage were significantly associated with higher risk of death in patients with lung carcinoma. It has been postulated that the persistence of neutrophils may result in further release of inflammatory mediators such as cytokines, proteases, and reactive oxygen and nitrogen species.

Concerning the role of IL-8 as an autocrine growth factor for lung tumour cells, the data is inconsistent. Recently, the current authors have shown that IL-8 is an important autocrine growth factor for A549 cells [34]. In addition, FUJISAWA et al. [35] showed that the inhibition of IL-8 binding to tumour cells inhibited tumour growth of adenocarcinoma A549 in vivo. However, another study demonstrated that A549 cells did not proliferate in response to IL-8 [36]. In summary, these data support the hypothesis that there is a feedback loop in tumour progression between tumour cells and inflammatory cells.

In conclusion, the present study has demonstrated that proteasome inhibition leads, in addition to the well-known suppression of proliferation and cell cycle progression, to an activator protein-1-dependent upregulation of interleukin-8 gene expression in different lung epithelial cell lines, primary lung epithelial cells, as well as in myeloid cell lines. Therefore, it should be considered that proteasome inhibitors may induce significant recruitment of inflammatory cells in addition to their role in the regulation of the cell cycle and apoptosis.

\section{References}

1. Rolfe M, Chiu MI, Pagano M. The ubiquitin-mediated proteolytic pathway as a therapeutic area. J Mol Med 1997; 75: $5-17$.

2. Anderson KC. Moving disease biology from the lab to the clinic. Cancer 2003; 97: 796-801.

3. Orlowski RZ, Eswara JR, Lafond-Walker A, Grever MR, Orlowski M, Dang CV. Tumor growth inhibition induced in a murine model of human Burkitt's lymphoma by a proteasome inhibitor. Cancer Res 1998; 58: 4342-4348.

4. Drexler HC. Activation of the cell death program by inhibition of proteasome function. Proc Natl Acad Sci USA 1997; 94: 855-860.

5. Pahl HL. Activators and target genes of Rel/NF-kappaB transcription factors. Oncogene 1999; 18: 6853-6866.

6. Adler KB, Fischer BM, Wright DT, Cohn LA, Becker S. Interactions between respiratory epithelial cells and cytokines: relationships to lung inflammation. Ann N Y Acad Sci 1994; 725: 128-145.

7. Koyama S, Sato E, Masubuchi T, et al. Procaterol inhibits IL-1beta- and TNF-alpha-mediated epithelial cell eosinophil chemotactic activity. Eur Respir $J$ 1999; 14: 767-775.

8. Lin Y, Zhang M, Barnes PF. Chemokine production by a human alveolar epithelial cell line in response to Mycobacterium tuberculosis. Infect Immun 1998; 66: 1121-1126.

9. Roux P, Alfieri C, Hrimech M, Cohen EA, Tanner JE. Activation of transcription factors NF-kappaB and NF-IL-6 by human immunodeficiency virus type 1 protein $\mathrm{R}$ (Vpr) induces interleukin-8 expression. J Virol 2000; 74: 4658-4665.

10. Olszewska-Pazdrak B, Casola A, Saito T, et al. Cell-specific expression of RANTES, MCP-1, and MIP-1alpha by lower airway epithelial cells and eosinophils infected with respiratory syncytial virus. J Virol 1998; 72: 4756-4764.

11. Roebuck KA, Carpenter LR, Lakshminarayanan V, Page SM, Moy JN, Thomas LL. Stimulus-specific regulation of chemokine expression involves differential activation of the redox-responsive transcription factors AP-1 and NF-kappaB. J Leukoc Biol 1999; 65: 291-298.

12. Fiedler MA, Wernke-Dollries K, Stark JM. Inhibition of TNF-alpha-induced NF-kappaB activation and IL-8 release in A549 cells with the proteasome inhibitor MG-132. Am J Respir Cell Mol Biol 1998; 19: 259-268.

13. Wu HM, Wen HC, Lin WW. Proteasome inhibitors stimulate interleukin- 8 expression via Ras and apoptosis signal-regulating kinase-dependent extracellular signalrelated kinase and c-Jun N-terminal kinase activation. Am J Respir Cell Mol Biol 2002; 27: 234-243.

14. Gerber A, Wille A, Welte T, Ansorge S, Buhling F. Interleukin-6 and transforming growth factor-beta 1 control expression of cathepsins B and L in human lung epithelial cells. J Interferon Cytokine Res 2001; 21: 11-19.

15. Schreiber E, Matthias P, Muller MM, Schaffner W. Rapid detection of octamer binding proteins with 'mini-extracts', prepared from a small number of cells. Nucleic Acids Res 1989; 17: 6419.

16. Gerber A, Struy H, Weiss G, Lippert H, Ansorge S, Schulz HU. Effect of granulocyte colony-stimulating factor treatment on ex vivo neutrophil functions in nonneutropenic surgical intensive care patients. I Interferon Cytokine Res 2000; 20: 1083-1090.

17. Alcorn MJ, Booth JL, Coggeshall KM, Metcalf JP. Adenovirus type 7 induces interleukin- 8 production via activation of extracellular regulated kinase $1 / 2$. J Virol 2001; 75: 6450-6459.

18. Watanabe N, Iwamoto T, Dickinson DA, Iles KE, Forman HJ. 
Activation of the mitochondrial caspase cascade in the absence of protein synthesis does not require c-Jun N-terminal kinase. Arch Biochem Biophys 2002; 405: 231240.

19. Kisselev AF, Goldberg AL. Proteasome inhibitors: from research tools to drug candidates. Chem Biol 2001; 8: 739-758.

20. Ling YH, Liebes L, Jiang JD, et al. Mechanisms of proteasome inhibitor PS-341-induced G(2)-M-phase arrest and apoptosis in human non-small cell lung cancer cell lines. Clin Cancer Res 2003; 9: 1145-1154.

21. Nakayama K, Furusu A, Xu Q, Konta T, Kitamura M. Unexpected transcriptional induction of monocyte chemoattractant protein 1 by proteasome inhibition: involvement of the c-Jun $\mathrm{N}$-terminal kinase-activator protein 1 pathway. J Immunol 2001; 167: 1145-1150.

22. Hipp MS, Urbich $\mathrm{C}$, Mayer $\mathrm{P}$, et al. Proteasome inhibition leads to NF-kappaB-independent IL-8 transactivation in human endothelial cells through induction of AP-1. Eur J Immunol 2002; 32: 2208-2217.

23. Smith RS, Fedyk ER, Springer TA, Mukaida N, Iglewski $\mathrm{BH}$, Phipps RP. IL-8 production in human lung fibroblasts and epithelial cells activated by the Pseudomonas autoinducer N-3-oxododecanoyl homoserine lactone is transcriptionally regulated by NF-kappa B and activator protein-2. J Immunol 2001; 167: 366-374.

24. Haas M, Page S, Page M, et al. Effect of proteasome inhibitors on monocytic IkappaB-alpha and -beta depletion, NF-kappaB activation, and cytokine production. J Leukoc Biol 1998; 63: 395-404.

25. Petit F, Jarrousse AS, Dahlmann B, et al. Involvement of proteasomal subunits zeta and iota in RNA degradation. Biochem J 1997; 326: 93-98.

26. Laroia G, Cuesta R, Brewer G, Schneider RJ. Control of mRNA decay by heat shock-ubiquitin-proteasome pathway. Science 1999; 284: 499-502.

27. Mastronarde JG, Monick MM, Mukaida N, Matsushima K, Hunninghake GW. Activator protein-1 is the preferred transcription factor for cooperative interaction with nuclear
factor-kappaB in respiratory syncytial virus-induced interleukin-8 gene expression in airway epithelium. $J$ Infect Dis 1998; 177: 1275-1281.

28. Rahman I, Gilmour PS, Jimenez LA, MacNee W. Oxidative stress and TNF-alpha induce histone acetylation and NFkappaB/AP-1 activation in alveolar epithelial cells: potential mechanism in gene transcription in lung inflammation. Mol Cell Biochem 2002; 234-235: 239-248.

29. Newton R, Cambridge L, Hart LA, Stevens DA, Lindsay MA, Barnes PJ. The MAP kinase inhibitors, PD098059, UO126 and SB203580, inhibit IL-1beta-dependent PGE(2) release via mechanistically distinct processes. Br J Pharmacol 2000; 130: 1353-1361.

30. Cuenda A, Rouse J, Doza YN, et al. SB 203580 is a specific inhibitor of a MAP kinase homologue which is stimulated by cellular stresses and interleukin-1. FEBS Lett 1995; 364 229-233.

31. Favata MF, Horiuchi KY, Manos EJ, et al. Identification of a novel inhibitor of mitogen-activated protein kinase kinase. J Biol Chem 1998; 273: 18623-18632.

32. Bennett BL, Sasaki DT, Murray BW, et al. SP600125, an anthrapyrazolone inhibitor of Jun N-terminal kinase. Proc Natl Acad Sci USA 2001; 98: 13681-13686.

33. Bellocq A, Antoine M, Flahault A, et al. Neutrophil alveolitis in bronchioloalveolar carcinoma: induction by tumor-derived interleukin-8 and relation to clinical outcome. Am J Pathol 1998; 152: 83-92.

34. Wille A, Heimburg A, Gerber A, Reisenauer A, Welte T, Buhling F. Functional consequences of cathepsin L deficiency in human lung epithelial cells. Biol Chem 2002; 383: $1291-1296$

35. Fujisawa N, Sakao Y, Hayashi S, Hadden WA, III, Harmon CL, Miller EJ. alpha-Chemokine growth factors for adenocarcinomas; a synthetic peptide inhibitor for alpha-chemokines inhibits the growth of adenocarcinoma cell lines. $J$ Cancer Res Clin Oncol 2000; 126: 19-26.

36. Murdoch C, Monk PN, Finn A. Functional expression of chemokine receptor CXCR4 on human epithelial cells Immunology 1999; 98: 36-41. 